\title{
OsO(IV) catalyzed oxidative decolorization of azo dye metanil yellow by bromamine -B in alkaline medium: Spectrophotmetric, kinetic and mechanistic approach
}

\author{
H.S Savitha ${ }^{\mathrm{a}, \mathrm{e}}$, J.P. Shubha ${ }^{\mathrm{b}}$, , Puttaswamy $^{\mathrm{c}}$, S. Nanjunda Swamy ${ }^{\mathrm{d}}$, B.S. Priya ${ }^{\mathrm{e}^{*}}$ \\ ${ }^{a}$ Department of Chemistry, SJB Institute of Technology, Bangalore - 560060 \\ ${ }^{b}$ Department of Chemistry, Don Bosco Institute of Technology, Kumbalagodu, Mysore Road, Bangalore-560 \\ 074 \\ ${ }^{c}$ Department of Chemistry, Bangalore University, Central College Campus, Bangalore-560001 ${ }^{d}$ Department of \\ Biotechnology, Sri Jayachamarajendra College of Engineering, JSS Technical Institutions Campus, Mysuru- \\ 570006 \\ ${ }^{e}$ Department of Studies in Chemistry, University of Mysore, Manasagangotri, Mysuru-570006
}

\begin{abstract}
The kinetics of oxidative decolorization of metanil yellow (MY) by Bromamine - $\mathrm{B}$ in NaOH medium in presence of $\mathrm{Os} O(I V)$ has been investigated spectrophotometrically $\left(\lambda_{\max }=414 \mathrm{~nm}\right)$ at $298 \mathrm{~K}$. Kinetic studies were performed under pseudo first-order conditions of $[B A B]_{o}>>[M Y]_{o}$. The reactions show first-order dependence each on $[B A B]_{o},[M Y]$ and $[\mathrm{OSO}(\mathrm{IV})]$, a fractional-order dependence on [NaOH]. Stoichiometry of the reaction was found to be 1:3 and the oxidation products were identified by spectral analysis. The reaction was studied at different temperatures and various activation parameters have been computed. Effects of benzenesulfonamide, ionic strength and dielectric constant of the medium have been studied. Reaction mixture fails to induce polymerization with acrylonitrile. Probable mechanism and relevant rate law have been deliberated for the observed kinetic results.
\end{abstract}

Key Words: Decolorization, Metanil Yellow, oxidation-kinetics, Bromamine-B, acid medium, Os $O(I V)$

\section{Introduction}

Food coloring, or color additive, is any dye, pigment or substance that imparts color when it is added to food or drink. They come in many forms consisting of liquids, powders, gels, and pastes. Food coloring is used both in commercial food production and in domestic cooking. [1] People associate certain colors with certain flavors, and the color of food can influence the perceived flavor in anything from candy to wine [2] . Variety of dyes used in textile industry usually has a synthetic origin and multifaceted aromatic molecular structures, which make them more stable and less amenable to biodegradation [3-5]. Metanil yellow is a mono azo dye and used as a colorant agent in many food industries. It is extensively used in the developing countries as a colorant in sweet meat, ice-creams, soft drinks, and beverages [6]. Because of its orange-yellow color, metanil yellow is also widely used in the coating of turmeric. It is extensively used in paper, leather, and many textile industries as a dye and colorant for the wool $[6,7]$. Moreover, it is also used as a colorant for lacquers and cosmetic products. Furthermore, the dye is highly suitable for the preparation of colored water-fast inks [8] and can also be used analytically for the determination of trace amounts of Mo (VI) [9]. Dyes used in the textile industry may be toxic to aquatic organisms and can be resistant to natural biological degradation $[10,11,12]$. Effluents containing azo dyes are commonly treated using physico-chemical methods such as adsorption, photo degradation and coagulation. All these processes are expensive and complicated. Therefore, there is a need for inexpensive and simple methods to abolish harmful dyes in effluents. The oxidation of azo dyes has attracted much attention in recent years [13-18]. The literature review reveals that there is no information on the oxidative decolorization of metanil yellow from kinetic and mechanistic view point. Consequently, this research program is designed through oxidative decolorization kinetic studies to determine the mechanism of this reaction. The effectiveness of the proposed process was evaluated by its ability to decrease in color and total organic carbon content. The high efficiency observed with the dye model showed that this economic, easily operated and maintained treatment process can also be employed in the remediation of effluents.

The diverse nature of the chemistry of N-haloamines is a result of their ability to act as sources of halonium cations, hypohalites and $\mathrm{N}$-anions which act both as electrophiles and nucleophiles [17-21]. They behave as mild oxidants and are suitable for the limited oxidation of several functional groups. Consequently, these reagents react with a wide variety of functional groups affecting an array of molecular transformations. Monohaloamines in common undergo two electron changes while dihaloamines act as four electron oxidants. The reduction products obtained are the respective sulfonamide and sodium chloride [22]. The leading members of this class of chlorocompounds are chloramine-T (CAT) and chloramine-B (CAB). A review of literature 
reveals that although the reaction of aromatic sulfonyl chloramines have been known and extensively investigated, [17,22-25] there is not much of information [18-21] available on the reaction of corresponding bromamines, bromamine-T and bromamine-B. Sodium N-bromobenzenesulfonamide or bromamine-B (BAB; $\mathrm{C}_{6} \mathrm{H}_{5} \mathrm{SO}_{2} \mathrm{NBrNa} 1.5 \mathrm{H}_{2} \mathrm{O} \mathrm{BAB}$ ) has gained importance as a mild oxidant and it can be readily prepared by brominating $\mathrm{CAB}$. Bromamine- $\mathrm{B}$ is found to be a most potential oxidant among these $\mathrm{N}$-haloamines. There are but a very few reports [26-29] on the kinetics of oxidation of organic substrates by $\mathrm{BAB}$ as compared to the studies with other haloamines as oxidants from mechanistic vision. For these grounds, it was felt motivating to explore the mechanism of oxidation of MY with this reagent. Accordingly, in this communication we report on the comprehensive $\mathrm{OsO}(\mathrm{IV})$ catalyzed oxidation kinetics of $\mathrm{MY}$ by $\mathrm{BAB}$ in $\mathrm{NaOH}$ medium at $298 \mathrm{~K}$.

\subsection{Materials}

\section{Experimental}

Bromamine-B was prepared [30] by the partial debromination of dibromamine-B (DBB) as follows. Pure chlorine was bubbled through an aqueous solution of chloramine-B (30 g in $560 \mathrm{~mL}$ water) and liquid bromine $(6 \mathrm{~mL})$ was added drop wise with invariable stirring. A yellow precipitate of DBB formed was washed well with $\mathrm{H}_{2} \mathrm{O}$, filtered under suction, and dried in a vacuum desiccator. Dibromamine-B (31.5 g) was digested in batches with constant stirring in $50 \mathrm{~mL}$ of $4 \mathrm{~mol} \mathrm{dm}^{-3} \mathrm{NaOH}$. The resulting mass was cooled in ice, filtered under suction, and the product (BAB) was dried over anhydrous calcium chloride. The purity of BAB was tested iodometrically through its active bromine content and its FT-IR spectrum. Aqueous solutions of BAB were prepared, standardized whenever required by the iodometric method and preserved in brown bottles to prevent its photochemical corrosion. Metanil Yellow (Sigma Aldrich) was used as received and aqueous solution of the dye was prepared fresh just before use. Solvent isotope studies were made with $\mathrm{D}_{2} \mathrm{O}(99.4 \%)$ supplied by BARC, Mumbai, India. Analytical grade chemicals and double distilled water was used throughout. The regression coefficient ( $\mathrm{r}$ ) was calculated using $f x-350 \mathrm{TL}$ scientific calculator

\subsection{Kinetic measurements}

Kinetic measurements were carried out using a Digital Spectrophotometer 166, Systronics, India. In the present study, the kinetic experiments were carried out between 288 and 313 K. For this purpose, a Raagaa Ultra Cold Chamber with digital temperature control (Chennai, India) was used. The temperature was maintained constant with an accuracy of $\pm 0.1{ }^{\circ} \mathrm{C}$. Detailed kinetic runs were performed under pseudo first-order conditions of $[\mathrm{BAB}]_{0}>>[\mathrm{MY}]_{0}$ at $298 \mathrm{~K}$. Reactions were conceded in glass stopper pyrex boiling tubes whose outer surfaces were coated black to avoid photochemical effects. The oxidant as well as the requisite amounts of MY, OsO(IV) and $\mathrm{NaOH}$ solutions and water (to keep the total volume constant for all runs) taken in separate tubes were thermostatted for $30 \mathrm{~min}$ at $298 \mathrm{~K}$. The reaction was initiated by the rapid addition of measured amount of oxidant to the stirred reaction mixture. Immediately, $4 \mathrm{~cm}^{3}$ of the solution was pipetted into a cuvette positioned in the UV-Vis spectrophotometer and absorbance dimensions were made at $414 \mathrm{~nm}\left(\lambda_{\max }\right.$ for MY) for more than two half-lives. The absorbance readings at $t=0$ and $t=t$ are $D_{0}$ and $D_{t}$. Plots of $\log D_{0} / D_{t}$ versus time were made to evaluate the pseudo first-order rate constants $\left(\mathrm{k}^{\prime}\right)$ which were found reproducible within $\pm 4-5 \%$.

\subsection{Reaction stoichiometry}

Reaction mixtures containing different ratios of $\mathrm{BAB}$ to $\mathrm{MY}$ in presence of $4.0 \times 10^{-2} \mathrm{moldm}^{-3} \mathrm{NaOH}$ were equilibrated at $298 \mathrm{~K}$ for $24 \mathrm{~h}$. The unreacted $\mathrm{BAB}$ in the reaction mixture was determined by iodometric titration. This analysis showed that in both the cases one mole of MY consumed three mole of BAB and the observed reaction stoichiometry is represented as:
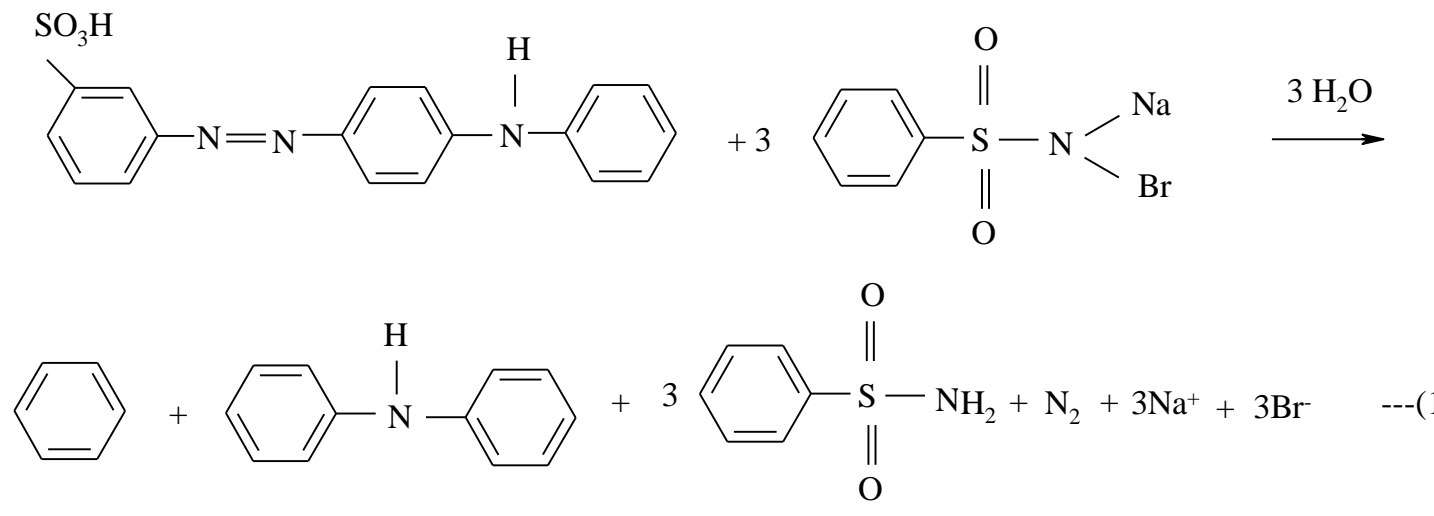
OsO(IV) catalyzed oxidative decolorization of azo dye metanil yellow by bromamine $-B$ in ....

\subsection{Product analysis}

In the stoichiometric proportion, the reaction mixtures containing different concentrations of oxidant and substrate in $2.0 \times 10^{-3} \mathrm{~mol} \mathrm{dm}^{-3} \mathrm{NaOH}$ under stirred condition was allowed to react for $24 \mathrm{~h}$ at $298 \mathrm{~K}$. After completion of the reaction (monitored by thin layer chromatography), the reaction products were neutralized with alkali and extracted with ether. The organic products were subjected to spot tests [34] and chromatographic analysis, which revealed the formation of benzene and biphenyl amine as the oxidation products of MY and benzene sulfonamide as the reduction product of the oxidant. These compounds were confirmed by mass spectral analysis. It was noticed that there was no reaction between the products and oxidant under the current set of experimental conditions.

$\mathrm{OsO}(\mathrm{IV})$ Ether- $\mathrm{CHCl}_{3}-1$-butanol $(2: 2: 1, \mathrm{v} / \mathrm{v})$ as a solvent system and iodine as a spray reagent $\quad\left(\mathrm{R}_{\mathrm{f}}=0.88\right)$.

\subsection{Effect of reactant concentration on the rate}

\section{Results And Discussion}

The kinetics of oxidation of MY by BAB has been investigated at several initial concentrations of the reactants, under pseudo first-order conditions of [oxidant $]_{0} \gg$ [substrate $]_{0}$ with $\mathrm{NaOH}$ in presence of OsO(IV) at $298 \mathrm{~K}$. Under this conditions at constant $[\mathrm{BAB}]_{\mathrm{o}},[\mathrm{NaOH}],[\mathrm{OsO}(\mathrm{IV})]$, temperature, plots of log (absorbance) versus time were linear $(r>0.9952)$ indicating a first-order dependence of rate on $[\mathrm{MY}]_{\mathrm{o}}$. The linearity of the plot with the constancy of the slope obtained at different $[\mathrm{MY}]_{\mathrm{o}}$, substantiates the first-order dependence of rate on $[\mathrm{MY}]_{0}$. The pseudo first-order rate constants $\left(\mathrm{k}^{\prime}\right)$ obtained are recorded in Table 1. Under the same experimental conditions the rate of reaction increased in $[\mathrm{BAB}]_{0}$ (Table 1) and plot of $\log \mathrm{k}^{\prime}$ versus $\log [\mathrm{BAB}]$ was linear $(r>0.9540)$ with unit slope. This establishes that the order of the reaction is first-order with respect to $[\mathrm{BAB}]_{0}$. Further, plot of $\mathrm{k}^{\prime}$ versus $[\mathrm{BAB}]_{0}$ were linear $(\mathrm{r}>0.9980)$ passing through the origin corroborate the first-order dependence on $[\mathrm{BAB}]_{0}$. The rate of reaction augmented with increase in $[\mathrm{NaOH}]($ Table 1) and plots of $\log$ $k$ versus $\log [\mathrm{NaOH}]$ was linear $(r>0.998)$ with slope of 0.85 , showing a fractional-order dependence on $[\mathrm{NaOH}]$.

\subsection{Effect of $O \mathrm{O} O(I V)$ concentration on the rate}

In alkaline medium the rate of the reaction increased by increasing [OsO(IV)] (Table 1) and a plot of $\log \mathrm{k}^{\prime}$ versus $\log [\mathrm{OsO}(\mathrm{IV})]$ was linear $(\mathrm{r}=0.9989)$ with a slope of 0.76 . This ensures that the order of reaction with respect to $[\mathrm{OsO}(\mathrm{IV})]$ is fractional.

\subsection{Effects of halide ions and p-benzenesulfonamide concentration on the rate}

Addition of halide ions, $\mathrm{Cl}^{-}$or $\mathrm{Br}^{-}$, in the form of their sodium salts $\left(1.0 \times 10^{-3}-8.0 \times 10^{-3} \mathrm{~mol} \mathrm{dm}^{-3}\right)$ showed no pronounced effect on the rate. This indicates that the halide ions play no role in the reaction. The ionic strength of the reaction medium was assorted from 0.2 to $0.8 \mathrm{~mol} \mathrm{dm}^{-3}$ with $\mathrm{NaClO}_{4}$ solution keeping other experimental conditions constant. It was found that addition of $\mathrm{NaClO}_{4}$ showed negligible effect on the reaction rate, representing the participation of nonionic species in the rate-determining step. Hence no attempts were made to maintain the ionic strength of the medium stable for kinetic runs. Addition of benzene sulfonamide $\left(\mathrm{PhSO}_{2} \mathrm{NH}_{2}\right)$ to the reaction mixture $\left(5.0 \times 10^{-3} \mathrm{~mol} \mathrm{dm}^{-3}\right)$ did not influence the rate significantly indicates that $\mathrm{PhSO}_{2} \mathrm{NH}_{2}$ is not involved in any step prior to the rate determining step of the proposed scheme.

\subsection{Effect of dielectric constant of the medium on the rate}

The dielectric constant (D) of the medium was mottled by adding $\mathrm{MeOH}(0-30 \% \mathrm{v} / \mathrm{v})$ to the reaction mixture with all other experimental conditions being held constant but the rates were not considerably altered with both the oxidants. Values of dielectric constant of $\mathrm{MeOH}-\mathrm{H}_{2} \mathrm{O}$ mixture reported in the literature [28] were used.

\subsection{Effect of temperature on the rate}

The reaction was studied at different temperatures (283-313 K), keeping other experimental conditions constant. From Arrhenius plot of $\log k^{\prime}$ vs. $1 / \mathrm{T}(r>0.9980)$, composite activation parameters $\left(\mathrm{E}_{\mathrm{a}}, \Delta \mathrm{H}^{\neq}, \Delta \mathrm{S}^{\neq}\right.$, $\Delta \mathrm{G}^{\ddagger}$ ) were computed for the oxidation of MY by BAB. These data are summarized in Table 3.

\subsection{Test for free radicals}

Alkene monomers such as acrylonitrile and freshly prepared $10 \%$ acrylamide solution were added to the reaction mixture to initiate polymerization by free radicals formed in situ. The lack of polymerization indicated the absence of free radicals in the reaction mixture. This clearly ruled out the possibility of free radical mechanism. The controlled experiments were also performed under similar reaction conditions without oxidant. 
Os $O(I V)$ catalyzed oxidative decolorization of azo dye metanil yellow by bromamine $-B$ in ....

\subsection{Reactive Species of $B A B$}

Organic haloamines have homogeneous chemical properties and hence it is expected that similar equilibria exist in solutions of these compounds [33-37] Bromamine- $\mathrm{B}$, which is analogous to chloramine-T and chloramine-B, behaves like a strong electrolyte both in acidic and alkaline media [34]. The oxidation potential of $\mathrm{BAB} / \mathrm{PhSO}_{2} \mathrm{NH}_{2}$ is $\mathrm{pH}$ dependent [17] and decreases with increase in the $\mathrm{pH}$ of the medium (1.4 $\mathrm{V}$ at $\mathrm{pH}$ 0.65 and $0.50 \mathrm{~V}$ at $\mathrm{pH} 12.0$ ). In acid solutions, $\mathrm{BAB}$ exists in the following equilibria:

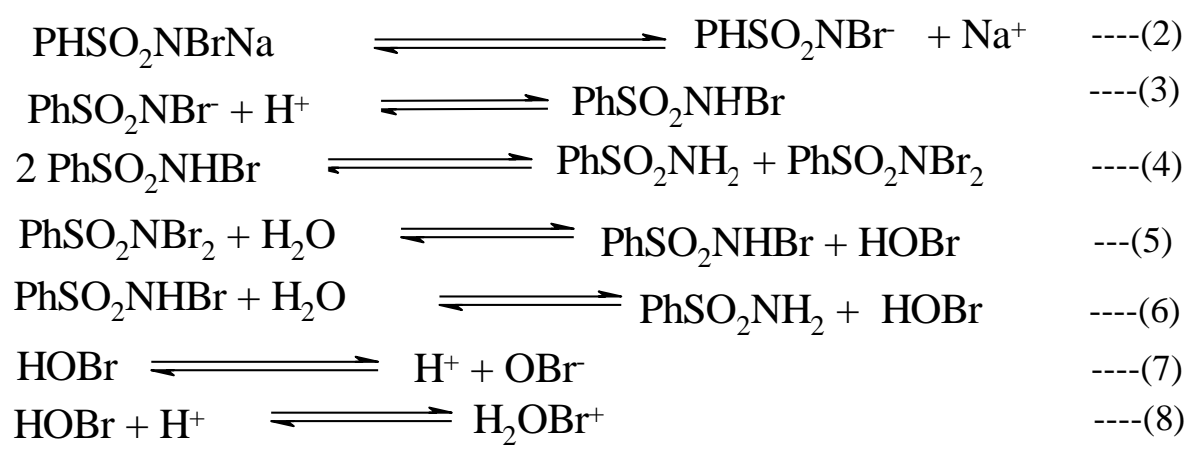

In alkaline solutions of $\mathrm{BAB}, \mathrm{PhSO}_{2} \mathrm{NBr}_{2}$ does not exist and hence the expected reactive species are $\mathrm{PhSO}_{2} \mathrm{NHBr}, \mathrm{HOBr}$ and $\mathrm{PhSO}_{2} \mathrm{NHBr}^{-}$. Further, Hardy and Johnston reported the following equilibria in alkaline solutions of bromamine-B.

$$
\begin{aligned}
& \mathrm{PhSO}_{2} \mathrm{NBr}^{-}+\mathrm{H}_{2} \mathrm{O} \rightleftharpoons \mathrm{PhSO}_{2} \mathrm{NHBr}+\mathrm{OH}^{-} \\
& \mathrm{PhSO}_{2} \mathrm{NHBr}+\mathrm{OH}^{-} \rightleftharpoons \mathrm{PhSO}_{2} \mathrm{NBr}^{-}+\mathrm{H}_{2} \mathrm{O}
\end{aligned}
$$

If $\mathrm{PhSO}_{2} \mathrm{NHBr}$ and $\mathrm{HOBr}$ were to be the reactive oxidizing species, according to Equations 9 and 10 , the retardation of rate by added $\mathrm{PhSO}_{2} \mathrm{NH}_{2}$ and $\mathrm{OH}^{-}$would be expected. Since no such effects were observed in the present investigations, these two species may be ruled out as reactive oxidizing species. Hence, the anion $\mathrm{PhSO}_{2} \mathrm{NBr}^{-}$is most likely to be the oxidizing species in alkali accelerating reactions. The same anion has been postulated as the reactive oxidizing species in our earlier work [23-25].

It has been shown that osmium has a stable +8 oxidation state and exists as trans-octahedral complexes of $\left[\mathrm{OsO}(\mathrm{IV})(\mathrm{OH})\left(\mathrm{H}_{2} \mathrm{O}\right)\right]^{-}$and $\left[\mathrm{OsO}(\mathrm{IV})(\mathrm{OH})_{2}\right]^{2-}$ in alkaline solutions according to the following equlibria [31,32]:

$$
\begin{aligned}
& \mathrm{OsO}_{4}+\mathrm{OH}^{-}+\mathrm{H}_{2} \mathrm{O} \rightleftharpoons\left[\mathrm{OsO}_{4}(\mathrm{OH})\left(\mathrm{H}_{2} \mathrm{O}\right)\right]^{-} \\
& {\left[\mathrm{OsO}_{4}(\mathrm{OH})\left(\mathrm{H}_{2} \mathrm{O}\right)\right]^{-}+\mathrm{OH}^{-} \rightleftharpoons\left[\mathrm{OsO}_{4}(\mathrm{OH})_{2}\right]^{2-}+\mathrm{H}_{2} \mathrm{O}}
\end{aligned}
$$

The complexes $\left[\mathrm{OsO}(\mathrm{IV})(\mathrm{OH})\left(\mathrm{H}_{2} \mathrm{O}\right)\right]^{-}$and $\left[\mathrm{OsO}(\mathrm{IV})(\mathrm{OH})_{2}\right]^{2-}$ which can be reduced to $\left[\mathrm{OsO}_{2}(\mathrm{OH})_{4}\right]^{2-}$ with octahedral geometries seem to be less likely to form species of higher coordination with the oxidantsubstrate species. It is more reasonable to postulate $\mathrm{OsO}_{4}$, which has tetrahedral geometry, is the active catalyst species that can effectively form a complex with the oxidant species in the present study.

Considering the above facts and all the experimental data, the following mechanism (Scheme 1) may be suggested for Os(VIII) catalyzed oxidation of MY by $\mathrm{BAB}$ in alkaline medium.

$$
\begin{array}{ll}
\mathrm{PhSO}_{2} \mathrm{NHBr}+\mathrm{OH}^{-} \rightleftharpoons \mathrm{PhSO}_{2} \mathrm{NBr}^{-}+\mathrm{H}_{2} \mathrm{O} & \text { fast (i) } \\
\mathrm{PhSO}_{2} \mathrm{NBr}^{-}+\mathrm{OsO}(\mathrm{IV}) \stackrel{\mathrm{K}_{2}}{\rightleftharpoons} \mathrm{X} & \text { fast (ii) } \\
\mathrm{X}+\mathrm{MY} \stackrel{\text { (complex) }}{\stackrel{\mathrm{k}_{3}}{\rightleftharpoons} \mathrm{X}^{\prime}} & \text { slow and r d s (iii) } \\
(\text { complex }) &
\end{array}
$$$$
\mathrm{X}^{\prime}+\mathrm{PhSO}_{2} \mathrm{NBr}^{-} \longrightarrow \text { ㄱoducts } \longrightarrow \text { fast (iv) }
$$

Scheme 1. General reaction scheme for the oxidation of MY by $\mathrm{BAB}$ in $\mathrm{NaOH}$ medium catalyzed by $\mathrm{OsO}$ (IV). 
Here $\mathrm{X}$ and $\mathrm{X}^{\prime}$ are the intermediate complex species whose structures are shown in Scheme 2, where a detailed mechanistic interpretation of $\mathrm{OsO}(\mathrm{IV})$ catalyzed oxidation of $\mathrm{MY}$ by $\mathrm{BAB}$ in alkaline medium is presented.

Step (iii) of Scheme 1 determines the overall rate,

Rate $=\mathrm{k}_{3}[\mathrm{X}][\mathrm{MY}]$

If $[\mathrm{BAB}]_{\mathrm{t}}$ represents the total effective concentration of $\mathrm{BAB}$ in solution, then

$[\mathrm{BAB}]_{\mathrm{t}}=\left[\mathrm{PhSO}_{2} \mathrm{NHBr}\right]+\left[\mathrm{PhSO}_{2} \mathrm{NBr}^{-}\right]+[\mathrm{X}]$, from which

$$
[\mathrm{X}]=\frac{\mathrm{K}_{1} \mathrm{~K}_{2}[\mathrm{BAB}]_{\mathrm{t}}\left[\mathrm{OH}^{-}\right][\mathrm{OsO}(\mathrm{IV})]}{\left[\mathrm{H}_{2} \mathrm{O}\right]+\mathrm{K}_{1}\left[\mathrm{OH}^{-}\right]+\mathrm{K}_{1} \mathrm{~K}_{2}\left[\mathrm{OH}^{-}\right][\mathrm{OsO}(\mathrm{IV})]}
$$

By substituting for $[\mathrm{X}]$ from Equation 14 into Equation 13, the following rate law is obtained.

$$
\text { Rate }=\frac{\mathrm{K}_{1} \mathrm{~K}_{2} \mathrm{k}_{3}[\mathrm{BAB}]_{\mathrm{t}}\left[\mathrm{OH}^{-}\right][\mathrm{MY}][\mathrm{OsO}(\mathrm{IV})]}{\left[\mathrm{H}_{2} \mathrm{O}\right]+\mathrm{K}_{1}\left[\mathrm{OH}^{-}\right]+\mathrm{K}_{1} \mathrm{~K}_{2}\left[\mathrm{OH}^{-}\right][\mathrm{OsO}(\mathrm{IV})]}
$$

Rate law (15) is in accordance with the experimental kinetic findings.

Since rate $=k[B A B]_{t}$, Equation 14 can be transformed into the following Equations 16-19:

$$
\begin{aligned}
& \mathrm{k}=\frac{\mathrm{K}_{1} \mathrm{~K}_{2} \mathrm{k}_{3}[\mathrm{MY}]\left[\mathrm{OH}^{-}\right]}{\left[\mathrm{H}_{2} \mathrm{O}\right]+\mathrm{K}_{1}\left[\mathrm{OH}^{-}\right]+\mathrm{K}_{1} \mathrm{~K}_{2}[\mathrm{OsO}(\mathrm{IV})]}-\frac{1}{\left[\mathrm{H}_{2} \mathrm{O}\right]}+\frac{1}{\mathrm{~K}_{2} \mathrm{k}_{3}[\mathrm{MY}]\left[\mathrm{OH}^{-}\right]}+\frac{1}{\mathrm{k}_{3}[\mathrm{MY}]} \\
& \left.\frac{1}{\mathrm{k}}=\frac{1}{\mathrm{~K}_{1} \mathrm{~K}_{2} \mathrm{k}_{3}[\mathrm{MY}]\left[\mathrm{OH}^{-}\right]}+\frac{1}{\mathrm{~K}_{2} \mathrm{k}_{3}[\mathrm{MY}]}\right)+\frac{1}{\mathrm{k}_{3}[\mathrm{MY}]} \\
& \frac{1}{\mathrm{k}}=\frac{1}{[\mathrm{OsO}(\mathrm{IV})]}\left(\frac{\left.1 \mathrm{H}_{2} \mathrm{O}\right]}{\mathrm{K}_{1} \mathrm{~K}_{2} \mathrm{k}_{3}[\mathrm{MY}]\left[\mathrm{OH}^{-}\right]}\right)+\frac{1}{\mathrm{~K}_{2} \mathrm{k}_{3}[\mathrm{MY}]}+\frac{1}{\mathrm{k}_{3}[\mathrm{MY}]}
\end{aligned}
$$

\subsection{Solvent Isotope Effect}

A positive methanol effect provides support for the proposed mechanism. For the limiting case of zero angle approach between two dipoles or an ion dipole system, Amis [41] showed that a plot of log k' versus 1/D gives a straight line with a negative slope for a reaction between a negative ion and a dipole or between two dipoles, whereas a positive slope results in a positive ion-dipole interaction. The latter concept agrees with the present observations, where a positive ion and a dipole are involved in the rate limiting step of Scheme 1.

The solvent isotope effect $k^{\prime}\left(\mathrm{H}_{2} \mathrm{O}\right) / k^{\prime}\left(\mathrm{D}_{2} \mathrm{O}\right)=0.69$ is noticed in alkaline medium. This is generally correlated with the greater basicity of $\mathrm{OD}^{-}$compared to $\mathrm{OH}^{-}$ions [42-43] which supports the initial equilibrium and rate limiting step in Scheme 3. However, the magnitude of retardation in $\mathrm{D}_{2} \mathrm{O}$ medium is small and can be attributed to the fractional order dependence on $[\mathrm{OH}]$ and may also be due to involvement of hydrolysis step in the rate limiting step. The mechanism proposed is consistent with the observed negligible effects of the addition of benzenesulfonamide, halide ions and ionic strength on the reaction rate and also on the activation parameters.

It was thought worthwhile to compare the reactivity of $\mathrm{MY}$ by $\mathrm{BAB}$ in the absence of $\mathrm{OsO}(\mathrm{IV})$ catalyst under the identical experimental conditions. The reaction was carried out at different temperatures $(283-313$ $\mathrm{K})$ and from the Arrhenius plot of $\log k^{\prime}$ versus $1 / \mathrm{T}(\mathrm{r}=0.9989)$, values of activation parameters for the uncatalyzed reaction were calculated. These data are also presented in Table 3. It is seen from Table 3 that in the $\mathrm{OsO}(\mathrm{IV})$ catalyzed reaction the rate is found to be nine times faster than the uncatalyzed reaction. Thus the observed rates of oxidation in the presence of $\mathrm{OsO}(\mathrm{IV})$ catalyst justify the need of a catalyst for a facile oxidation of the MY by BAB in alkaline medium. The activation parameters evaluated for the catalyzed and uncatalyzed reactions explain the catalytic effect on the reaction. The catalyst OsO(IV) forms a complex (X') with the oxidizing species, which increases the oxidizing property of the oxidant than without $\mathrm{OsO}(\mathrm{IV})$ catalyst. 
Further, the catalyst $\mathrm{OsO}(\mathrm{IV})$ favorably modifies the reaction path by lowering the energy of activation (Table 3).

Moelwyn-Hughes [40] pointed out that the catalyzed and uncatalyzed reactions proceed simultaneously and the relationship is

$\mathrm{k}_{1}=\mathrm{k}_{0}+\mathrm{K}_{\mathrm{C}}[\text { catalyst }]^{\mathrm{x}}$

Here $\mathrm{k}_{1}$ is the observed pseudo-first-order rate constant obtained in the presence of $\mathrm{OsO}(\mathrm{IV})$ catalyst, $\mathrm{k}_{0}$ is that for the uncatalyzed reaction, $\mathrm{K}_{\mathrm{C}}$ is the catalytic constant and $\mathrm{x}$ is the order of the reaction with respect to $\mathrm{OsO}(\mathrm{IV})$ and is found to be 0.76 in the present study. The value of $\mathrm{K}_{\mathrm{C}}$ is calculated using the equation $\mathrm{K}_{\mathrm{C}}=\left(\mathrm{k}_{1}-\mathrm{k}_{0}\right) /[\mathrm{OsO}(\mathrm{IV})]^{0.76}$

The values of $\mathrm{K}_{\mathrm{C}}$ have been evaluated at different temperatures (283-313 $\mathrm{K}$ ) and $\mathrm{K}_{\mathrm{C}}$ was found to vary with temperature. Further, a plot of $\log \mathrm{K}_{\mathrm{C}}$ versus $1 / \mathrm{T}$ was linear $(\mathrm{r}=0.9896)$ and the values of energy of activation and other thermodynamic parameters for the catalyst were computed and tabulated in Table 4.

The different oxidizing species of BAB involved in the two media may be responsible for the difference in reactivity. Thus the conjugate acid of $\mathrm{BAB}, \mathrm{PhSO}_{2} \mathrm{NHCl}$, is efficient reactive species than the anion, $\mathrm{PhSO}_{2} \mathrm{NCl}^{-}$ . Such a behavior has been noticed in our early work [23].

\subsection{Dielectric constant effect}

Reactions in aqueous medium that are vulnerable to acid-base catalysis have been studied in heavy water $\left(\mathrm{D}_{2} \mathrm{O}\right)$ after equilibrium. Since the majority oxidation reactions of organic compounds involve the cleavage of $\mathrm{C}-\mathrm{H}$ bond, deuterium isotope effect on such reaction gives information regarding the nature of the rate limiting step. In the present investigations, solvent isotope studies have shown that the rate of reaction is higher in $\mathrm{D}_{2} \mathrm{O}$ medium. For a reaction involving a fast equilibrium $\mathrm{H}^{+}$or $\mathrm{OH}^{-}$ion transfer, the rate increases in $\mathrm{D}_{2} \mathrm{O}$ medium since $\mathrm{D}_{3} \mathrm{O}^{+}$or $\mathrm{OD}^{-}$are a stronger acid and a stronger base respectively, than $\mathrm{H}_{3} \mathrm{O}^{+}$and $\mathrm{OH}^{-}$ions $[42,43]$. The observed solvent isotope effect of $k^{\prime}\left(\mathrm{H}_{2} \mathrm{O}\right)$ and $k^{\prime}\left(\mathrm{D}_{2} \mathrm{O}\right)<1$ is due to the greater acidity of $\mathrm{D}_{3} \mathrm{O}^{+}$ compared to $\mathrm{H}_{3} \mathrm{O}^{+}$. However, the magnitude of increase in rate in $\mathrm{D}_{2} \mathrm{O}$ is small (expected value is 2-3 times greater). This may be due to the fractional order dependence of rate on $\left[\mathrm{H}^{+}\right]$. Hence, this observation supports the planned mechanism. The negligible influence of difference of ionic strength and addition of benzenesulfonamide and halide ions are in conformity with the proposed mechanism. The proposed mechanism is also supported by the sensible value of energy of activation and other thermodynamic parameters (Table 3 ). The moderately high positive values of $\Delta G^{\ddagger}$ and $\Delta H^{\ddagger}$ designate the transition state is solvated while the negative entropy of activation replicates the formation of a dense and planned transition state. Further, the experimental observation demonstrates that there is no effect of benzenesulfonamide, halide ions and ionic strength on the reaction rate which also substantiates the predictable mechanism.

In the present redox system the optimum conditions for the controlled oxidation of MY by BAB were established in acid medium. Accordingly, this redox system can be scaled up to industrial process. Also, this method offers several advantages including short reaction time, cost helpful and reasonably non-toxic reagents which make the reaction process trouble-free, neat and environmentally kind

\section{Conclusions}

The kinetics of oxidation of MY by BAB in alkaline medium obeys the rate law $-\mathrm{d}$ [oxidant] $/ \mathrm{dt}=\mathrm{k}$ $[\mathrm{BAB}]_{\mathrm{o}}[\mathrm{MY}] \mathrm{o}\left[\mathrm{OH}^{-}\right]^{0.85}[\mathrm{OsO}(\mathrm{IV})]^{0.76}$. Oxidation products were identified by spot test spectral analysis. However, oxidation of MY with BAB in alkaline medium will become facile in presence of a micro quantity of $\mathrm{OsO}(\mathrm{IV})$ catalyst and reaction rates showed that $\mathrm{OsO}(\mathrm{IV})$ catalyzed reactions are nine times than uncatalyzed reactions. Therefore, OsO(IV)acts as an efficient catalyst in the oxidation of MY by BAB in alkaline medium. The observed results have been explained by plausible mechanisms and the related rate laws have been deduced. The present method developed for the oxidative decolorization of MY with BAB offers several advantages including cost efficient and fairly non-toxic reagents, which make the reaction course simple, smooth and environmentally compassionate. Furthermore, the simple and well-designed method developed in the present research can be implemented for treating MY present in industrial effluents to diminish the toxicity caused by this dye.

\section{References:}

[1]. CFR Title 21 Part 70: Color Additive Regulations, FDA, retrieved Feb 15, 2012

[2]. Jeannine Delwiche Food Quality and Preference 14 (2): 137-146. doi:10.1016/S0950-3293(03)00041-72003.

[3]. Zollinger, H., Colour chemistry: Synthesis, properties and applications of organic dyes and pigments, New York, VCH, 1981.

[4]. Perkowski, J., Ledakowicz, S., Fibres Text East Eur. 10, 68 (2002)

[5]. Waters, B.D., Colour in Dyehouse Effluent, Cooper, P. Ed. Society of Dyers and Colourists, Bradford, 1995.

[6]. S. Gupta, M. Sundarrajan, and K. V. K. Rao, Teratogenesis Carcinogenesis and Mutagenesis, supplement 1, pp. 301-312, 2003.

[7]. P. K. Seth, F. N. Jaffery, and V. K. Khanna, Indian Journal of Pharmacology, vol. 32, no. 4, pp. S134-S151, 2000.

[8]. E. W. Zimmerman, ” Industrial \& Engineering Chemistry, vol. 25, no. 9, pp. 1033-1034, 1933.

[9]. S. Wang, L. Du, A. Zhang, C. Ma, and D. Liu, ” MikrochimicaActa, vol. 124, no.1-2, pp. 49-54, 1996. 
Os $O(I V)$ catalyzed oxidative decolorization of azo dye metanil yellow by bromamine $-B$ in ....

[10]. Perkowski, J.; Ledakowicz, S. Fibres Text East Eur. 2002,10, 72.

[11]. Pearce, C.I.; Lloyd, J.R.; Guthrie, J.T. Dyes Pigments 2003, 58, 179-196.

[12]. Umbuzeiro, G.D.A.; Freeman, H.S.; Warren, S.H. De Oliveira, D.P.; Terao, Y.; Watanabe, T. Claxton, L.D. Chemosphere 2005, 60, 55-64.

[13]. Oakes, J.; Gratton, P. J. Chem. Soc. Perkin Trans 21998, 2201 and references therein.

[14]. Puttaswamy,; Shubha, J.P. Jagadeesh, R.V.; TransitionMetal Chem.2007, 32, 991,

[15]. Puttaswamy,; Vinod, K.N.: Ninge Gowda, K.N. Dyes pigments, 2008, 78, 131-138.

[16]. Vinod, K.N.; Puttaswamy;,Ninge Gowda, K.N. Inorg. Chim. Acta, 2009, 362, 2044-2051.

[17]. Campbell, M.M.; Johnson, G.Chem. Rev. 1978, 78, 65-79.

[18]. Banerji, K.K.; Jayaram, B.; Mahadevappa, D.S. J. Sci. Ind. Res. 1987, 46, 65-76.

[19]. Agarwal, M.C.; Upadhyay, S.K. J. Sci. Ind. Res. 1990, 49, 13.

[20]. Armesto, X.L.; Canle, L.; Garia, M.V.; Santaballa, J. Chem. Soc. Rev.1998, 27, 453.

[21]. Kolvari, E.E.; Ghorbani-Chogamarani, A.; Salehi,P.; Shirini, F.; Zolfigol, M.A. J. Iran. Chem. Soc, 2007, 4, 126-174.

[22]. Murthy, A. R. V.; Rao, B. S. Proc Indian Acad. Sci. 1952, 35, 69.

[23]. Brenner, D. H. In. Synth. Reagents 1985, 6, 9 .

[24]. Gowda, B. T.; Mahadevappa, D. S. J. Chem. Soc. Perkin Trans.II 1983, 323

[25]. Geethanjali, A. Synlett. 2005, 18, 2857

[26]. Meenakshisundaram, SP.; Markkandan, R. Indian J. Chem. 2005, 44A, 71.

[27]. Usha, K. M.; Gowda, B. T. J. Che. Sci. 2006, 118, 351.

[28]. Shubha J P, Puttaswamy, Bull. Korean, Chem. Soc., 2009, 30(9), 1939.

[29]. Shubha J.P., Y. Madhusudhan, Puttaswamy, Int. J. Inno. Res. Sci., 2015, 4(3), 817-828.

[30]. Ahmed, M. S.; Mahadevappa, D. S. Talanta 1980, 27, 669.

[31]. F.A. Cotton, G. Wilkinson, C.A. Murillo, M. Bochmann, Advanced Inorganic Chemistry, 6th ed., John-Wiley and Sons. Inc., New York, 1999.

[32]. W.P. Griffith, The Chemistry of Rare Platinum Metals, InterScience, New York, 1967.

[33]. Morris, J. C.; Salazar, J. A.; Wineman, M. A. J. Am. Chem. Soc.1948, 70, 2036.

[34]. Feigl F, Spot tests in Organic Analysis, 7th Edn., pp. 479-481. Elsevier, Amsterdam.

[35]. Bishop, E.; Jennings, V. J. Talanta 1959, 1, 197.

[36]. Hardy, F. F.; Johnston, J. P. J. Chem. Soc. Perkin Trans II 1973, 742.

[37]. Pryde, B. G.; Soper, F. G. J. Chem. Soc. 1962, 1582.

[38]. Narayanan, S. S.; Rao, V. R. S. Radio Chim. Acta 1983, 32, 211.

[39]. Subhashini, M.; Subramanian, M.; Rao, V. R. S. Talanta 1985, 32, 1082.

[40]. Moelwyn-Hughes, E.A. The kinetics of reaction in solutions, Oxford, Clarender Press, 374-381, 1947.

[41]. Amis, E.S. Rates Anal Chem 1955, 27, 1672-1679.

[42]. Collins CJ, Bowman NS Isotope Effects in Chemical Reactions New York, Van- Nostrand, 267, 1970

[43]. K.B. Wieberg, Chem. Rev., 55, 712 (1955).

Table 1. Effect of variation of $\mathrm{BAB}, \mathrm{MY}, \mathrm{NaOH}$ and $\mathrm{OsO}(\mathrm{IV})$ concentrations on the reaction rate at $298 \mathrm{~K}$.

\begin{tabular}{lcccc}
\hline $\begin{array}{l}10^{3}[\mathrm{BAB}]_{\circ} \\
\left(\mathrm{mol} \mathrm{dm}^{-3}\right)\end{array}$ & $\begin{array}{c}10^{4}[\mathrm{MY}]_{\circ} \\
\left(\mathrm{mol} \mathrm{dm}^{-3}\right)\end{array}$ & $\begin{array}{c}10^{3}[\mathrm{NaOH}] \\
\left(\mathrm{mol} \mathrm{dm}^{-3}\right)\end{array}$ & $\begin{array}{c}10^{5}[\mathrm{OsO}(\mathrm{IV})] \\
\left(\mathrm{mol} \mathrm{dm}^{-3}\right)\end{array}$ & $\begin{array}{c}10^{4} k^{\prime} \\
\left(\mathrm{s}^{-1}\right)\end{array}$ \\
\hline 0.5 & 1.8 & 1.4 & 1.2 & 1.84 \\
1.0 & 1.8 & 1.4 & 1.2 & 4.19 \\
2.0 & 1.8 & 1.4 & 1.2 & 8.16 \\
3.6 & 1.8 & 1.4 & 1.2 & 11.6 \\
5.0 & 1.8 & 1.4 & 1.2 & 8.6 \\
2.0 & 0.5 & 1.4 & 1.2 & 7.86 \\
2.0 & 1.0 & 1.4 & 1.2 & 8.16 \\
2.0 & 1.8 & 1.4 & 1.2 & 8.35 \\
2.0 & 2.6 & 1.4 & 1.2 & 7.92 \\
2.0 & 4.0 & 1.4 & 1.2 & 2.50 \\
2.0 & 1.8 & 0.2 & 1.2 & 5.92 \\
2.0 & 1.8 & 0.8 & 1.2 & 13.8 \\
2.0 & 1.8 & 1.4 & 1.2 & 18.7 \\
2.0 & 1.8 & 3.0 & 1.2 & 3.82 \\
2.0 & 1.8 & 4.0 & 1.2 & 5.35 \\
2.0 & 1.8 & 1.4 & 0.6 & 8.10 \\
2.0 & 1.8 & 1.4 & 0.8 & 11.5 \\
2.0 & 1.8 & 1.4 & 1.2 & 16.7 \\
2.0 & 1.8 & 1.4 & 2.0 & \\
2.0 & 1.8 & 1.4 & 3.0 & \\
\hline
\end{tabular}

$[\mathrm{BAB}]=2.0 \times 10^{-3} \mathrm{~mol} \mathrm{dm}^{-3} ;[\mathrm{MY}]=2.0 \times 10^{-4} \mathrm{~mol} \mathrm{dm}^{-3} ;[\mathrm{NaOH}]=4.0 \times 10^{-2} \mathrm{~mol} \mathrm{dm}^{-3} ;$ $[\mathrm{OsO}(\mathrm{IV})]=1.2 \times 10^{-5} \mathrm{~mol} \mathrm{dm}^{-3}$. 
OsO(IV) catalyzed oxidative decolorization of azo dye metanil yellow by bromamine $-B$ in ....

Table 2. Effect of dielectric constant on the reaction rate at $298 \mathrm{~K}$.

\begin{tabular}{ccc}
\hline$\% \mathrm{MeOH}(\mathrm{v} / \mathrm{v})$ & $\mathrm{D}$ & $10^{4} k^{\prime}\left(\mathrm{s}^{-1}\right)$ \\
\hline 0 & 76.73 & 8.16 \\
5 & 74.50 & 6.52 \\
10 & 72.37 & 5.70 \\
20 & 67.48 & 4.40 \\
30 & 62.71 & 2.96 \\
\hline $\mathrm{BAB}]=2.0 \times 10^{-3} \mathrm{~mol} \mathrm{dm}^{-3} ;[$ Metanil Yellow $]=2.0 \times 10^{-4} \mathrm{~mol} \mathrm{dm}^{-3} ;[\mathrm{NaOH}]=4.0 \times 10^{-2} \mathrm{moldm}^{-3}$ \\
{$[\mathrm{OsO}(\mathrm{IV})]=1.2 \times 10^{-5} \mathrm{~mol} \mathrm{dm}^{-3}$.}
\end{tabular}

Table 3. Temperature dependence on the reaction rate and activation parameters for the oxidation of Metanil Yellow by $\mathrm{BAB}$ in alkaline medium

\begin{tabular}{lr}
\hline Temperature $(\mathrm{K})$ & $10^{4} k^{\prime}\left(\mathrm{s}^{-1}\right)$ \\
\hline 283 & $3.16(0.42)$ \\
288 & $4.85(0.54)$ \\
298 & $8.16(0.90)$ \\
303 & $12.6(1.28)$ \\
313 & $24.7(2.74)$ \\
$\mathrm{E}_{\mathrm{a}}\left(\mathrm{kJ} \mathrm{mol}^{-1}\right)$ & $47.8(57.4)$ \\
$\Delta H^{\ddagger}\left(\mathrm{kJ} \mathrm{mol}^{-1}\right)$ & $46.0(54.9)$ \\
$\Delta G^{\neq}\left(\mathrm{kJ} \mathrm{mol}^{-1}\right)$ & $90.3(95.7)$ \\
$\Delta S^{\ddagger}\left(\mathrm{JK}^{-1} \mathrm{~mol}^{-1}\right)$ & $-151(-137)$ \\
\hline
\end{tabular}

$[\mathrm{BAB}]=2.0 \times 10^{-3} \mathrm{~mol} \mathrm{dm}^{-3} ;[\mathrm{MY}]=1.8 \times 10^{-4} \mathrm{~mol} \mathrm{dm}^{-3} ;[\mathrm{NaOH}]=1.4 \times 10^{-3} \mathrm{~mol} \mathrm{dm}^{-3}$ $[\mathrm{OsO}(\mathrm{IV})]=1.2 \times 10^{-5} \mathrm{~mol} \mathrm{dm}^{-3}$.

Table 4. Values of catalytic constant $\left(\mathrm{K}_{\mathrm{C}}\right)$ at different temperatures and activation parameters calculated using $\mathrm{K}_{\mathrm{C}}$ values

\begin{tabular}{ll}
\hline Temperature $(\mathrm{K})$ & $\mathrm{K}_{\mathrm{C}}$ \\
\hline 283 & 1.75 \\
288 & 2.36 \\
298 & 3.98 \\
303 & 6.14 \\
313 & 12.06 \\
$\mathrm{E}_{\mathrm{a}}\left(\mathrm{kJ} \mathrm{mol}^{-1}\right)$ & 32.81 \\
$\Delta H^{\ddagger}\left(\mathrm{kJ} \mathrm{mol}^{-1}\right)$ & 30.34 \\
$\Delta G^{\ddagger}\left(\mathrm{kJ} \mathrm{mol}^{-1}\right)$ & 69.34 \\
$\Delta S^{\ddagger}\left(\mathrm{JK}^{-1} \mathrm{~mol}^{-1}\right)$ & -131.15 \\
\hline
\end{tabular}

$[\mathrm{BAB}]=2.0 \times 10^{-3} \mathrm{~mol} \mathrm{dm}^{-3} ;[\mathrm{MY}]=1.8 \times 10^{-4} \mathrm{~mol} \mathrm{dm}^{-3} ;[\mathrm{NaOH}]=1.4 \times 10^{-3} \mathrm{~mol} \mathrm{dm}^{-3}$

$[\mathrm{OsO}(\mathrm{IV})]=1.2 \times 10^{-5} \mathrm{~mol} \mathrm{dm}^{-3}$. 


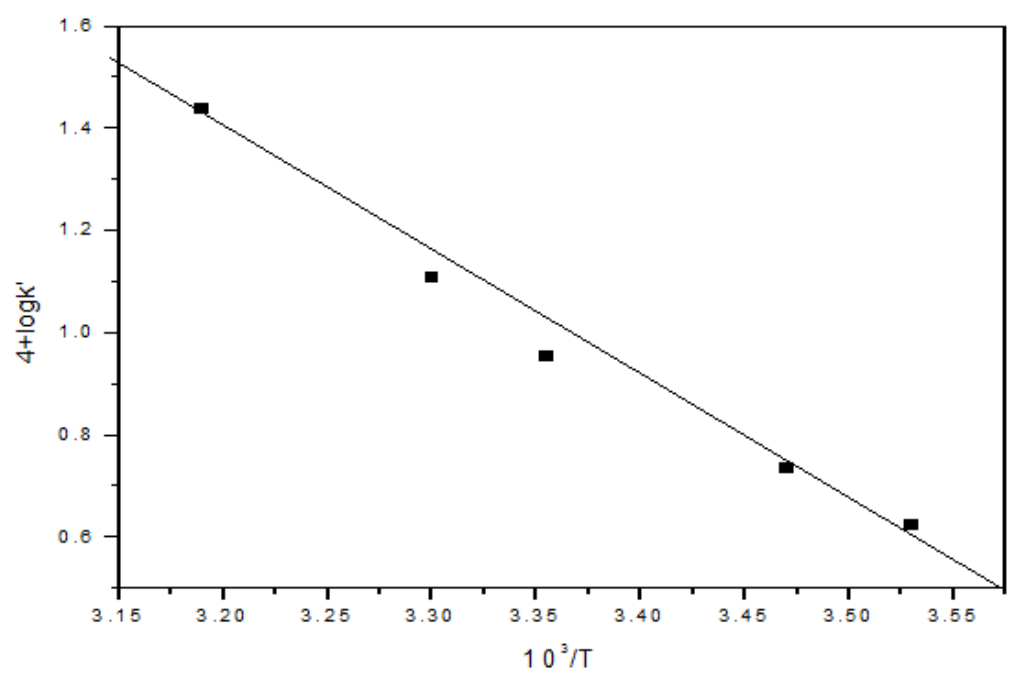

Figure 1. Plot of $1 / \mathrm{T}$ versus $\log \mathrm{k}^{\prime}$ for uncatalyzed reaction

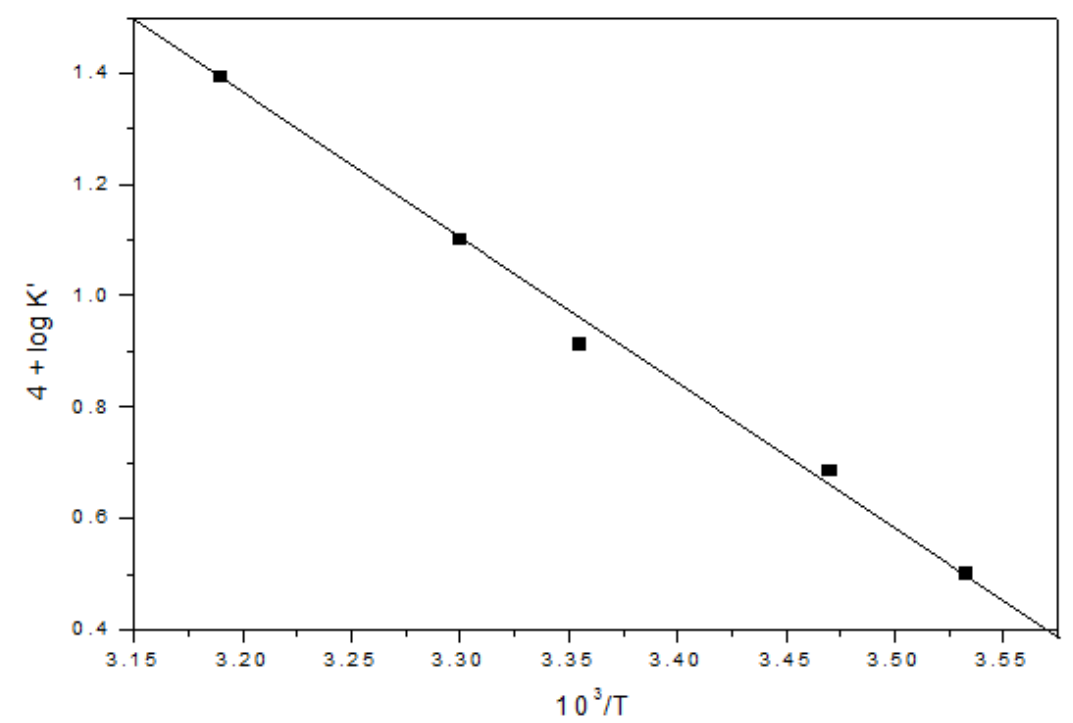

Figure 2. Plot of $1 / \mathrm{T}$ versus $\log \mathrm{k}^{\prime}$ for $\mathrm{OsO}(\mathrm{IV})$ catalyzed reaction.

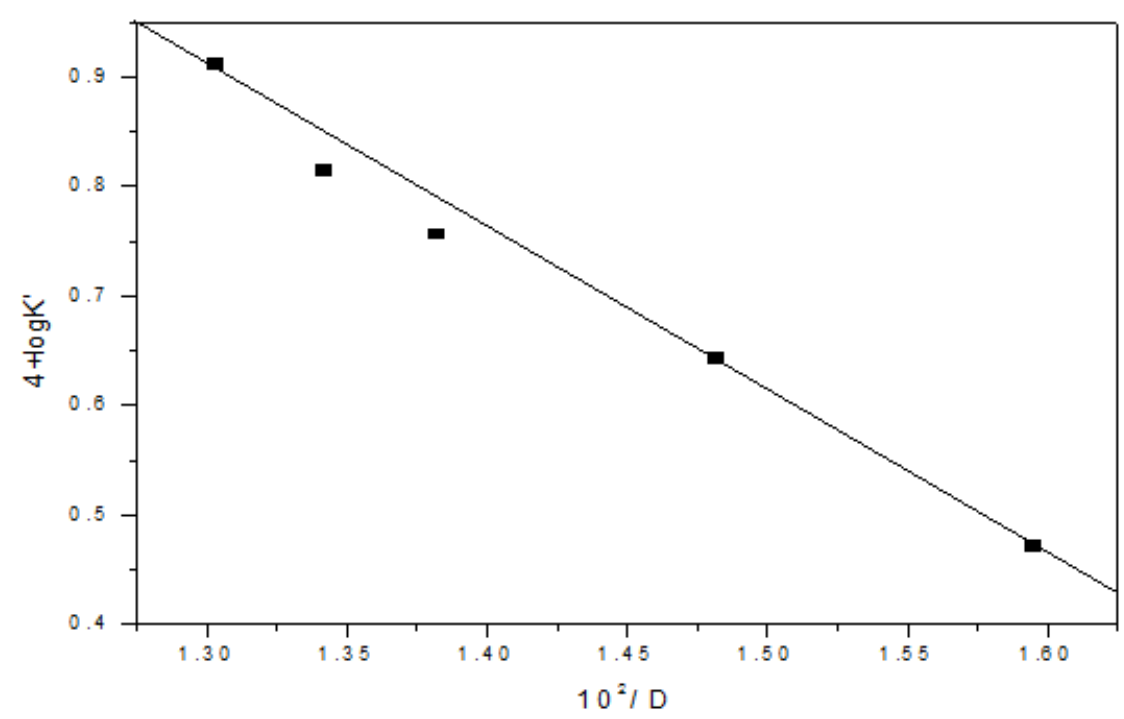

Figure 3. Plot of 1/D versus $\log \mathrm{k}^{\prime}$. 
(i) $\mathrm{PhSO}_{2} \mathrm{NHBr}+\mathrm{OH}^{-} \rightleftharpoons \mathrm{PhSO}_{2} \mathrm{NBr}^{-}+\mathrm{H}_{2} \mathrm{O}$

(ii)

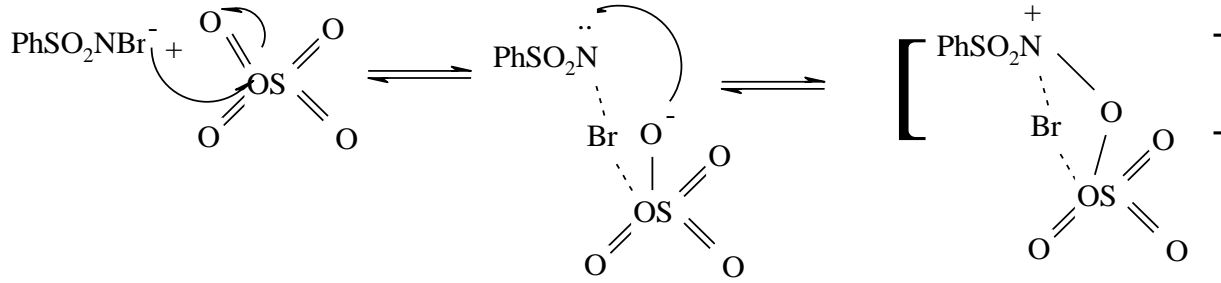

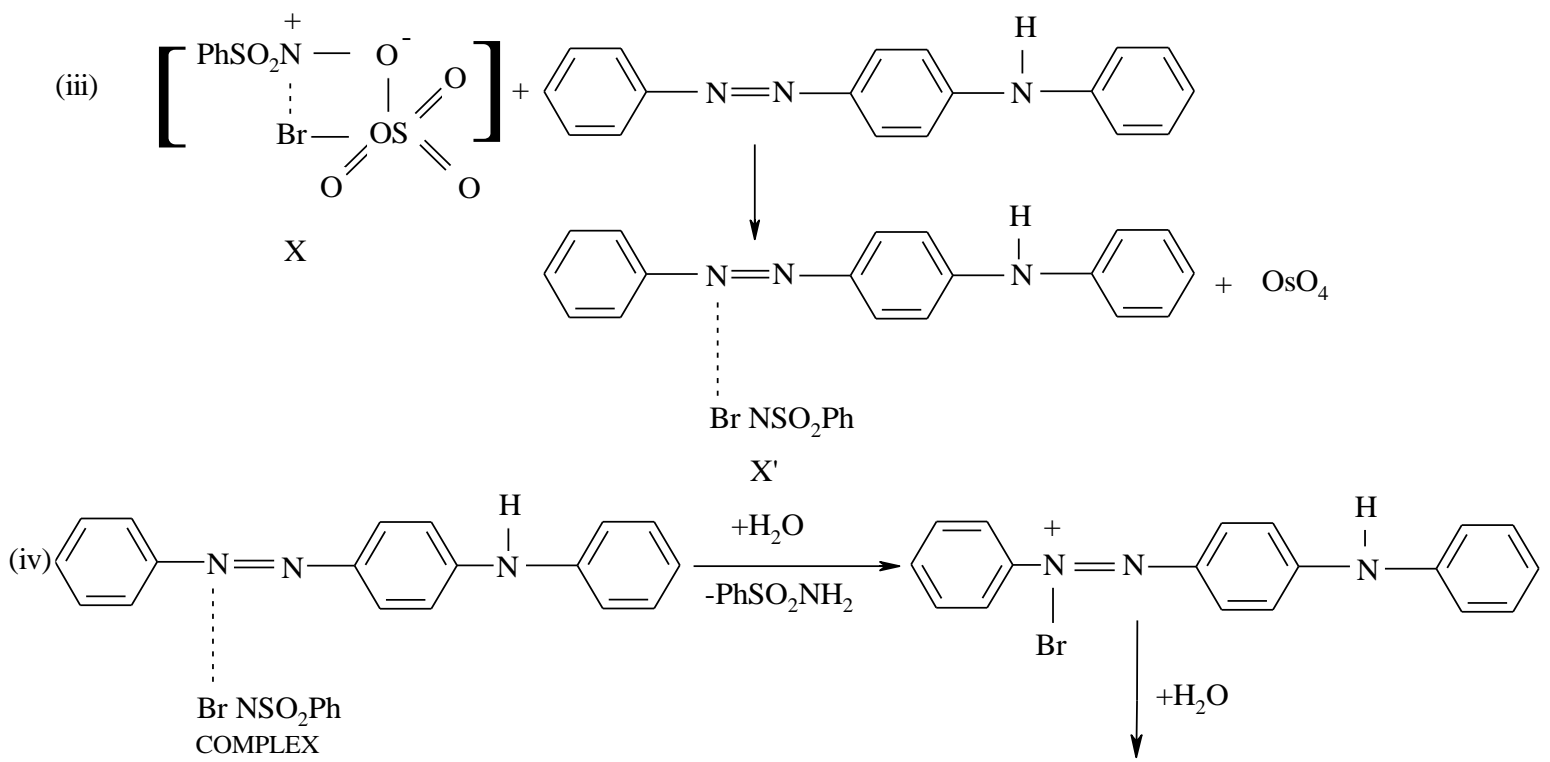<smiles>CCc1ccc(NNc2ccc([N+](C)(C)N(C)c3ccccc3)cc2)cc1</smiles>
$\mathrm{PhSO}_{2} \mathrm{~N}^{-} \mathrm{Br}$<smiles></smiles>

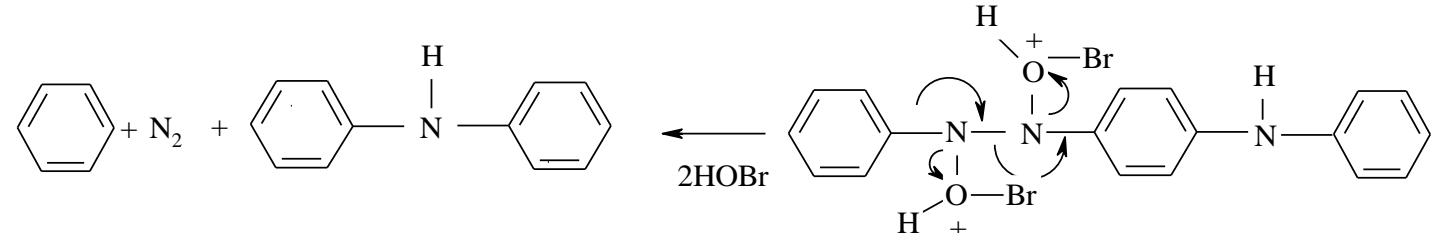

Scheme 2. Detailed mechanism of OsO(IV) catalyzed oxidation of metanil yellow by BAB in alkaline medium. 


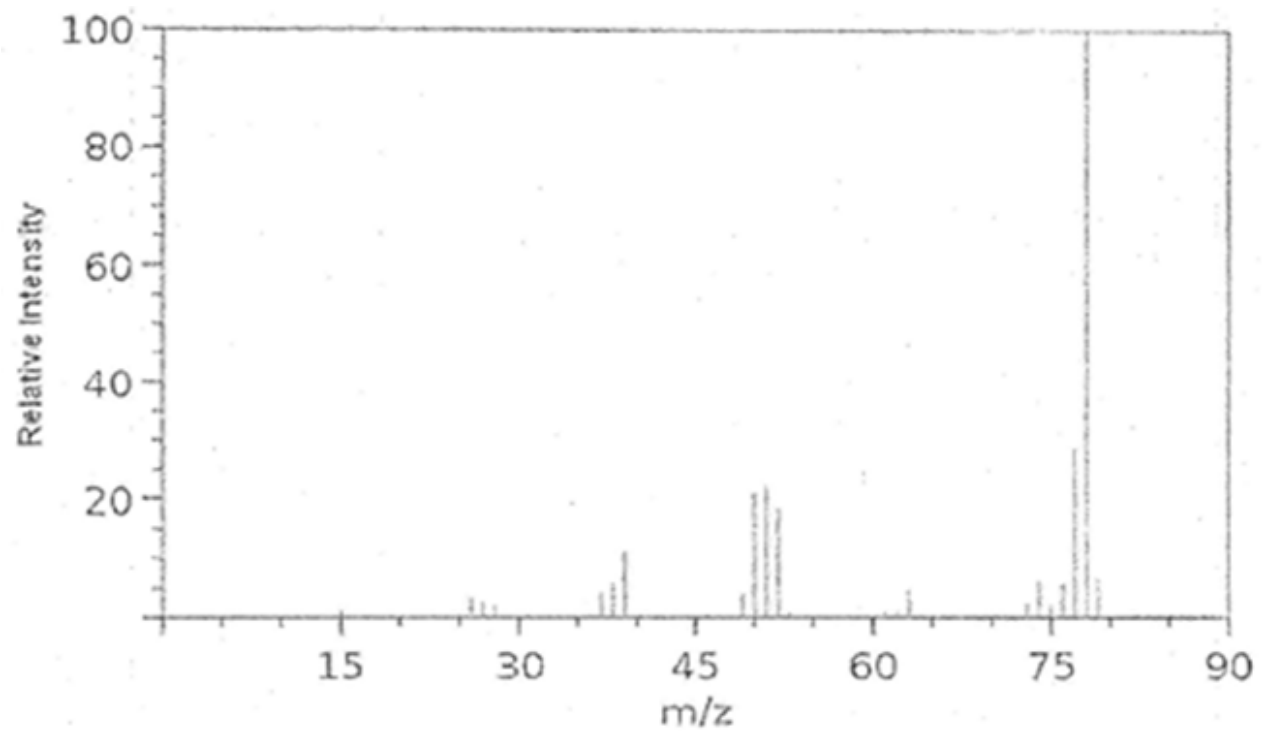

Figure 4. GC- Mass spectrum of benzene with its molecular ion peak at $78 \mathrm{amu}$.

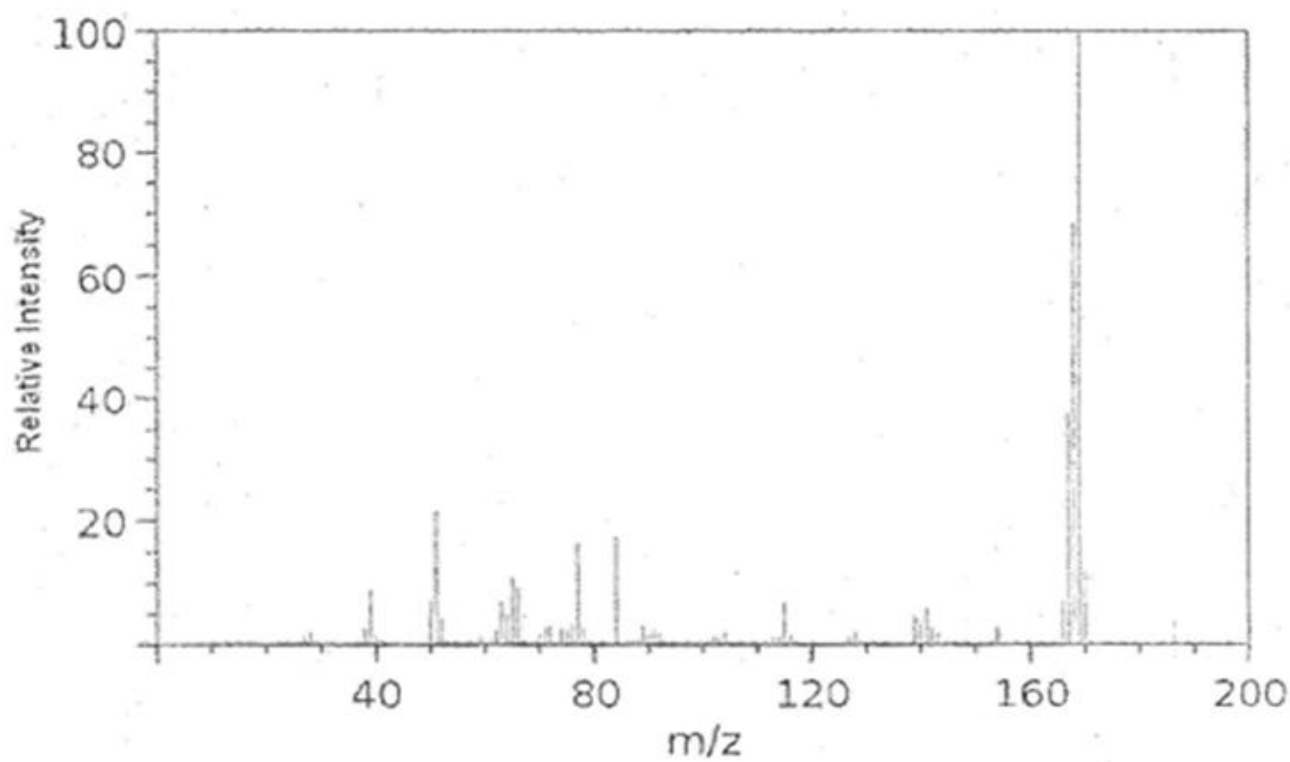

Figure 5. GC- Mass spectrum of N,N-biphenylamine molecular ion peak at 169 amu. 